\title{
Mini review of mercury contamination in environment and human with an emphasis on Malaysia: status and needs
}

\begin{abstract}
This article provides an overview of research on mercury $(\mathrm{Hg})$ contamination in Malaysia and its evolution from 1979 to 2012. The objective of this paper was to review and provide an understanding of $\mathrm{Hg}$ exposures in the environment, humans, and food in Malaysia. $\mathrm{Hg}$ concentration in the environment is high in areas of West Port, Malacca Straits, Prai, and Johor because these areas receive anthropogenic metal loads brought about by industrial activities. $\mathrm{Hg}$ concentration in humans is related to seafood intake (dietary), environmental conditions, and different geographical locations. $\mathrm{Hg}$ levels in food showed higher concentration in the West coast of Peninsular Malaysia. Hg concentration is also present in the countryôs tropical fruits, which is related to agrochemical and fertilizer usage. This review showed that there is an urgent need to identify $\mathrm{Hg}$ toxicology and bioaccumulation as well as the health effects of $\mathrm{Hg}$ exposure in different ecological compartments. This review aims to provide helpful recommendations for future $\mathrm{Hg}$ biomonitoring and research in Malaysia.
\end{abstract}

Keyword: Contamination; Human health; Malaysia; Mercury 